\title{
Interlitter variation in progeny of chimaeric male mice
}

\author{
Mia Buehr and Anne McLaren \\ M.R.C. Mammalian Development Unit, University College London, 4 Stephenson Way, \\ London NWI 2HE, U.K.
}

\begin{abstract}
Summary. Three chimaeric male mice $(\mathrm{C} 57 \mathrm{BL} / 6 \mathrm{McL} \leftrightarrow \mathrm{BALB} / \mathrm{c})$ were allowed to mate freely with $B A L B / c$ females, and produced two types of progeny: agouti (BALB/c egg $\times$ C57BL spermatozoon) and albino (BALB/c egg $\times$ BALB/c spermatozoon). The proportion of each type, however, varied significantly from litter to litter. The variation could not be related to the age of the male, or to the particular female who produced the litter, nor had it a clear cyclic pattern. Unilateral orchidectomy of one male resulted in a change in the overall frequency of progeny types observed, but did not alter the degree of interlitter variation. Females were then introduced to two of the males overnight $(18: 00-09: 00 \mathrm{~h})$ or during the day $(09: 00-18: 00 \mathrm{~h})$ in mouse rooms with a dark period from 19:00 to $05: 00 \mathrm{~h}$. Overnight matings produced a slight increase in the proportion of albino progeny, but daytime matings resulted in a significant increase in agouti young $(P<0.001)$. The relative proportions of the two types of progeny in litters of these males therefore appeared to be affected by the time of mating relative to the time of ovulation in the female, suggesting that variation in the time of mating is responsible for the observed interlitter variation in progeny type. Electrophoretic analysis of GPI-1 from spermatogenic cells isolated from the testes of one of the chimaeric males after death showed that the proportions of the two cell types in the testes were closer to the progeny proportions obtained from overnight than from daytime matings.
\end{abstract}

\section{Introduction}

Chimaeric mice resulting from the aggregation of two cleavage-stage embryos can have one of three sex-chromosome constitutions: $\mathrm{XX} \leftrightarrow \mathrm{XX}, \mathrm{XY} \leftrightarrow \mathrm{XY}$ or $\mathrm{XX} \leftrightarrow \mathrm{XY}$. Animals of the first two types can be germ-line chimaeras: that is, they may have functional gametes derived from both the cell lines that constitute the chimaera. If derived from two genetically distinct strains the germ-line chimaera can, when mated, yield progeny of two different types, one representing each of its constitutive cell lines. In the past the assumption has of ten been made that the relative frequency of each type of progeny produced by germ-line chimaeras reflects the relative frequency of each type of gamete in the gonad (see McLaren, 1978). However, interpretation of the breeding records of chimaeric males is often complicated by the fact that the proportions of progeny types in litters sired by these males can fluctuate significantly from litter to litter (McLaren, 1975; Gearhart \& Oster-Granite, 1981). On the other hand, no interlitter variation was seen by E. T. Mystkowska in progeny of chimaeric mice derived from two closely-related strains (personal communication to McLaren, 1978). McLaren (1975) has suggested that patchiness of germ-cell populations within or between the testes could account for varied proportions of sperm types within successive ejaculations. Another explanation has been proposed by J. Cohen (personal communication) who suggests that variation in the time of mating relative to ovulation in the female might affect progeny type. In this study we attempt to define the source of interlitter variation in the progeny of chimaeric males. 


\section{Materials and Methods}

\section{Animals}

Aggregation chimaeras were produced as previously described (Bowman \& McLaren, 1970) between 8-cell embryos of the inbred strains BALB/c (obtained from the Clinical Research Centre, Harrow, Middlesex in 1980 and derived by them from mice imported from the Jackson Laboratories in 1955) and C57BL/6McL. These two strains differ in coat colour and carry different structural alleles for the enzymes glucosephosphate isomerase (GPI-1 : EC 5.3.1.9): BALB/c mice are albino and carry the allele coding for the A alloenzyme, while C57BL mice are black and express the B alloenzyme. Male mice derived from embryo aggregation that were coat-colour chimaeras were assessed for germ-like chimaerism by testing their ability to produce both white and agouti progeny when mated to BALB/c females. The BALB/c $\times$ C57BL F1 (resulting from the fertilization of the BALB/c egg by a C57BL spermatozoon) is a dark-eyed agouti, while the BALB/c egg fertilized by a BALB/c spermatozoon produces a pink-eyed albino young. Three male germ-line chimaeras were produced: No. 1 (born January 1980) and Nos 18 and 19 (born November 1981). Chimaeras 1 and 18 were estimated to have $50 \%$ albino and $50 \%$ pigmented hair, and Chimaera 19 to have $40 \%$ albino and $60 \%$ pigmented hair. All 3 males were mated to nulliparous BALB/c females (although the males were sometimes allowed to sire more than one litter from the same female) and all the mice in the study were maintained in the same mouse room, with a dark period extending from 19:00 to $05: 00 \mathrm{~h}$.

Ad-libitum matings. Males were kept caged with 4 females at a time: as these became visibly pregnant they were removed and replaced with others. No attempt was made to determine the time of mating. Litters were scored at birth for eye colour.

Timed matings. Groups of 4 females were put with each male (Nos 18 and 19 only) at $09: 00 \mathrm{~h}$, and checked for vaginal plugs at $18: 00 \mathrm{~h}$. They were then removed and replaced with another group of 4 which was checked for plugs at $09: 00 \mathrm{~h}$ the next morning. Litters resulting from daytime and overnight matings were scored at birth for eye colour.

\section{GPI-1 analysis}

After the breeding programme was completed, the testes were removed from Chimaera 18 and the seminiferous tubules collected according to a modification of the method developed by Bellvé, Millette, Bhaturgar \& O'Brien (1977). Samples of tubules collected from mature males by this method contain about $3 \%$ Sertoli cells but $<1 \%$ contamination from other somatic elements. The seminiferous tubules were removed from the tunica albuginea and incubated in a collagenase solution $\left(0.5 \mathrm{mg}\right.$ collagenase $/ \mathrm{ml}$ phosphate-buffered saline) at $20^{\circ} \mathrm{C}$ for $30 \mathrm{~min}$. Sections of tubule $1.5 \mathrm{~cm}$ in length were then freed from adhering interstitial cells and frozen individually in finely-drawn Pasteur pipettes. Samples were freeze-thawed 3 times before electrophoresis on cellulose acetate gels ("Titan III Iso-Viz" plates from Helena Laboratories, obtainable from M.I. Scientific, Airport Industrial Estate, Kenton, Newcastle upon Tyne, U.K.) which was carried out as previously described (McLaren \& Buehr, 1981). After staining, the agar overlay was removed from the gel plates which were fixed in $5 \%$ acetic acid for $5 \mathrm{~min}$, washed in distilled water for $20 \mathrm{~min}$, and dried. The gels were scanned on a Gelman DCD- 16 computing densitometer which calculated the relative activities contributed to the total sample activity by the component alloenzymes. The analysis of these samples was complicated by the existence of minor bands running anodal to the major GPI-1 bands in samples of normal mouse spermatogenic tissue (Buehr \& McLaren, 1981). In gels of chimaeric seminiferous tubules the minor band associated with the $B$ alloenzyme was located in the position also occupied by the major $A$ band. The calculated activity of the $A$ bands had thus to be reduced by a factor equivalent to the intensity of the minor $B$ band (determined, after analysis of 
pure B samples, to be 0.21 of the activity of the major $B$ band). In the final calculations the activities of all minor bands were ignored, and only the relative activities of the major A and B bands considered.

\section{Results}

\section{Breeding results}

The ad-libitum breeding records of the 3 chimaeric males are presented in Tables 1 and 2 . For all 3 males, although albino and agouti young were produced, the proportion of each type varied significantly from litter to litter $\left(P<0.001\right.$ when tested by the $\chi^{2} 2 \times \mathrm{K}$ contingency table). There

Table 1. Litters derived from ad-libitum matings of Chimaera 1

\begin{tabular}{|c|c|c|c|c|c|}
\hline \multicolumn{3}{|c|}{ Intact male } & \multicolumn{3}{|c|}{ After unilateral orchidectomy } \\
\hline & \multicolumn{2}{|c|}{ Progeny type } & \multirow[b]{2}{*}{ Date of birth } & \multicolumn{2}{|c|}{ Progeny type } \\
\hline Date of birth & Agouti & Albino & & Agouti & Albino \\
\hline 15 May 1980 & 4 & 1 & 2 July 1981 & 0 & 9 \\
\hline 4 June 1980 & 0 & 6 & 12 July 1981 & 2 & 3 \\
\hline 5 June 1980 & 2 & 1 & 21 July 1981 & 2 & 0 \\
\hline 10 June 1980 & 0 & 7 & 27 July 1981 & 2 & 5 \\
\hline 23 June 1980 & 3 & 6 & 28 July 1981 & 1 & 1 \\
\hline 16 July 1980 & 1 & 6 & 12 August 1981 & 3 & 3 \\
\hline 2 October 1980 & 3 & 2 & 17 August 1981 & 3 & 3 \\
\hline 28 October 1980 & 0 & 8 & 27 August 1981 & 1 & 3 \\
\hline 1 November 1980 & 0 & 5 & 3 September 1981 & 1 & 0 \\
\hline 11 December 1980 & 1 & 4 & 21 September 1981 & 6 & 1 \\
\hline 17 December 1980 & 0 & 5 & 30 September 1981 & 0 & 1 \\
\hline 1 January 1981 & 0 & 9 & 8 October 1981 & 1 & 0 \\
\hline 15 February 1981 & 3 & 7 & 9 October 1981 & 0 & 8 \\
\hline 20 February 1981 & 0 & 11 & 18 October 1981 & 5 & 0 \\
\hline 1 March 1981 & 0 & 7 & 12 December 1981 & 6 & 0 \\
\hline 4 March 1981 & 0 & 10 & & & \\
\hline 11 March 1981 & 2 & 8 & & 33 & 37 \\
\hline 22 March 1981 & 1 & 7 & & $(47 \%)$ & $(53 \%)$ \\
\hline 27 March 1981 & 1 & 3 & & & \\
\hline 31 March 1981 & 1 & 6 & & & \\
\hline 5 April 1981 & 3 & 2 & & & \\
\hline 6 April 1981 & 0 & 8 & & & \\
\hline 21 April 1981 & 0 & 4 & & & \\
\hline 22 April 1981 & 0 & 7 & & & \\
\hline 30 April 1981 & 0 & 8 & & & \\
\hline 14 May 1981 & 4 & 5 & & & \\
\hline 24 May 1981 & 0 & 1 & & & \\
\hline 14 June 1981 & 1 & 9 & & & \\
\hline \multirow[t]{2}{*}{20 June 1981} & 0 & 9 & & & \\
\hline & $\begin{array}{c}30 \\
(15 \%)\end{array}$ & $\begin{array}{l}172 \\
(85 \%)\end{array}$ & & & \\
\hline
\end{tabular}

was no clear cyclic pattern to this interlitter variation, nor did it appear to change with the age of the male. When males were allowed to sire two litters from the same female (Table 3) no consistent similarity in the proportions of agouti and albino progeny could be seen between litters. When Chimaera 1 was subjected to unilateral orchidectomy and allowed to continue breeding (Table 1) interlitter variation continued to be significant, although the mean frequences of albino and agouti progeny in all litters differed significantly $(P<0.001)$ from those in the litters produced before surgery. 
Table 2. Litters derived from ad-libitum matings of Chimaeras 18 and 19

\begin{tabular}{|c|c|c|c|c|c|}
\hline \multicolumn{3}{|c|}{ Chimaera 18} & \multicolumn{3}{|c|}{ Chimaera 19} \\
\hline & \multicolumn{2}{|c|}{ Progeny type } & \multirow[b]{2}{*}{ Date of birth } & \multicolumn{2}{|c|}{ Progeny type } \\
\hline Date of birth & Agouti & Albino & & Agouti & Albino \\
\hline 27 January 1982 & 2 & 4 & 5 February 1982 & 10 & 0 \\
\hline 29 January 1982 & 2 & 7 & 9 February 1982 & 5 & 1 \\
\hline 14 February 1982 & 5 & 3 & 24 February 1982 & 2 & 6 \\
\hline 25 February 1982 & 5 & 3 & 25 February 1982 & 3 & 5 \\
\hline 4 March 1982 & 6 & 1 & 16 March 1982 & 0 & 8 \\
\hline 17 March 1982 & 5 & 2 & 18 March 1982 & 0 & 7 \\
\hline 18 March 1982 & 1 & 7 & 24 March 1982 & 4 & 4 \\
\hline 23 March 1982 & 2 & 6 & 25 March 1982 & 7 & 0 \\
\hline 24 March 1982 & 0 & 7 & 8 April 1982 & 0 & 6 \\
\hline 8 April 1982 & 5 & 5 & 10 April 1982 & 6 & 0 \\
\hline 8 April 1982 & 2 & 5 & 11 April 1982 & 9 & 1 \\
\hline 16 April 1982 & 0 & 11 & 10 May 1982 & 2 & 2 \\
\hline 7 May 1982 & 1 & 2 & 18 May 1982 & 4 & 4 \\
\hline 19 May 1982 & 3 & 0 & 21 May 1982 & 8 & 1 \\
\hline 20 May 1982 & 0 & 7 & 21 May 1982 & 3 & 1 \\
\hline 27 May 1982 & 3 & 3 & 6 June 1982 & 1 & 7 \\
\hline 10 June 1982 & 0 & 10 & 15 June 1982 & 0 & 7 \\
\hline \multirow[t]{3}{*}{12 June 1982} & 3 & 6 & 25 June 1982 & 2 & 5 \\
\hline & \multirow{2}{*}{$\begin{array}{c}45 \\
(34 \%)\end{array}$} & \multirow{2}{*}{$\begin{array}{c}89 \\
(66 \%)\end{array}$} & 26 June 1982 & 0 & 5 \\
\hline & & & & $\begin{array}{c}66 \\
(49 \%)\end{array}$ & $\begin{array}{l}70 \\
(51 \%)\end{array}$ \\
\hline
\end{tabular}

Table 3. Pairs of litters produced by the same female, sired by chimaeric males

\begin{tabular}{|c|c|c|c|c|c|c|c|}
\hline \multirow[b]{2}{*}{ Male } & \multirow[b]{2}{*}{ Female } & \multicolumn{3}{|c|}{ Litter 1} & \multicolumn{3}{|c|}{ Litter 2} \\
\hline & & Date of birth & Agouti & Albino & Date of birth & Agouti & Albino \\
\hline \multirow[t]{4}{*}{18} & 1 & 27 January 1982 & 2 & 4 & 24 March 1982 & 0 & 7 \\
\hline & 2 & 29 January 1982 & 2 & 7 & 23 March 1982 & 2 & 6 \\
\hline & 3 & 25 February 1982 & 5 & 3 & 20 May 1982 & 0 & 7 \\
\hline & 4 & 8 April 1982 & 5 & 5 & 10 June 1982 & 0 & 10 \\
\hline \multirow[t]{3}{*}{19} & 5 & 5 February 1982 & 10 & 0 & 18 May 1982 & 4 & 4 \\
\hline & 6 & 25 February 1982 & 3 & 5 & 21 May 1982 & 8 & 1 \\
\hline & 7 & 16 March 1982 & 0 & 8 & 10 April 1982 & 6 & 0 \\
\hline
\end{tabular}

Analysis of the litters resulting from overnight matings of Chimaeras 18 and 19 (Table 4) showed a drop in the total proportion of agouti young from both males, but this was significant $(P<0.01)$ only for Chimaera 19 . However, daytime matings resulted in a rise in the number of agouti young (Table 4 ) which was significant for both males $(P<0.001)$. The proportions of male and female progeny in all groups did not differ significantly from the expected $1: 1$ ratio.

\section{Electrophoretic analysis}

In all, 119 segments of seminiferous tubules from Chimaera 18 were examined for the relative contribution of BALB/c (GPI-1A) and C57BL (GPI-1B) components; 64 from the left testis and 55 from the right. The results are presented in Text-fig. 1. The mean contribution to the total GPI-1 activity made by GPI-1A was $66 \%$ in the left testis and $51 \%$ in the right $(P<0.01)$ : both testes together had a mean of $59 \%$ GPI-1 A activity in the seminiferous tubules. 
Table 4. Litters from timed matings of Chimaeras 18 and 19

\begin{tabular}{|c|c|c|c|c|c|}
\hline \multicolumn{3}{|c|}{ Overnight matings } & \multicolumn{3}{|c|}{ Daytime matings } \\
\hline \multirow[b]{2}{*}{ Date of birth } & \multicolumn{2}{|c|}{ Progeny type } & \multirow[b]{2}{*}{ Date of birth } & \multicolumn{2}{|c|}{ Progeny type } \\
\hline & Agouti & Albino & & Agouti & Albino \\
\hline \multicolumn{6}{|l|}{ Chimaera 18} \\
\hline 4 May 1982 & 4 & 3 & 25 April 1982 & 7 & 0 \\
\hline 7 June 1982 & 1 & 6 & 16 May 1982 & 5 & 1 \\
\hline 13 June 1982 & 2 & 6 & 18 May 1982 & 7 & 0 \\
\hline 21 July 1982 & 1 & 7 & 20 May 1982 & 1 & 5 \\
\hline 21 July 1982 & 0 & 7 & 23 May 1982 & 9 & 0 \\
\hline 10 September 1982 & 2 & 5 & 1 June 1982 & 6 & 0 \\
\hline 13 September 1982 & 0 & 7 & 15 June 1982 & 4 & 0 \\
\hline \multirow{3}{*}{16 October 1982} & 2 & 0 & 18 June 1982 & 1 & 6 \\
\hline & & & 10 September 1982 & 4 & 0 \\
\hline & $\begin{array}{l}12 \\
(23 \%)\end{array}$ & $\begin{array}{c}41 \\
(77 \%)\end{array}$ & & $\begin{array}{c}44 \\
(79 \%)\end{array}$ & $\begin{array}{l}12 \\
(21 \%)\end{array}$ \\
\hline \multicolumn{6}{|l|}{ Chimaera 19} \\
\hline 7 June 1982 & 6 & 4 & 13 May 1982 & 5 & 1 \\
\hline 15 June 1982 & 0 & 9 & 16 May 1982 & 6 & 0 \\
\hline 4 July 1982 & 0 & 9 & 8 June 1982 & 5 & 2 \\
\hline \multirow{3}{*}{21 July 1982} & 0 & 8 & 12 July 1982 & 6 & 0 \\
\hline & & & 20 July 1982 & 2 & 1 \\
\hline & $\begin{array}{c}6 \\
(17 \%)\end{array}$ & $\begin{array}{l}30 \\
(83 \%)\end{array}$ & & $\begin{array}{c}24 \\
(86 \%)\end{array}$ & $\begin{array}{c}4 \\
(14 \%)\end{array}$ \\
\hline
\end{tabular}



Text-fig. 1. Percentage of GPI-1A in seminiferous tubules of Chimaera 18.

\section{Discussion}

When allowed unrestricted access to females, all 3 of our chimaeric males sired litters that demonstrated interlitter variation similar to that previously reported (McLaren, 1975; Gearhart \& Oster-Granite, 1981). Analysis of GPI-1 from sections of seminiferous tubules of Chimaera 18 indicated that the two testes differed in the proportion of cells from each constituent strain that contributed to the seminiferous epithelium, while the fact that the removal of one testis of 
Chimaera 1 altered the overall frequency of progeny genotype also suggested that the frequencies of the two types of germ cells were different in the two testes. However, interlitter variation remained high even after removal of one testis and so cannot be attributed to differential contributions from the two testes to different ejaculates.

Our data support the hypothesis put forward by $\mathbf{J}$. Cohen (personal communication) that variation between litters reflects variation in the time of mating relative to ovulation, since they establish that the time of mating plays a significant part in determining the genotype of the progeny. In this, our results resemble those of Braden (1958) who found that changing the time of mating relative to the time of ovulation in the female could change the transmission ratios of certain alleles of the $t$ series.

Braden \& Austin (1954) and Braden (1957) established that in laboratory mice ovulation normally occurs 3-6 h after the midpoint of the dark period, and that coitus normally precedes ovulation by about $5 \mathrm{~h}$. In these circumstances some $6 \mathrm{~h}$ elapse between coitus and the fertilization of the egg. If the mating is delayed until after ovulation (as in our daytime mating) the interval between coitus and fertilization is much shorter: 2 h or less (Braden \& Austin, 1954).

In 1939 Dunn \& Gluecksohn-Schoenheimer reported that when males heterozygous at the $t$ locus were allowed free access to females, some $t$ alleles were transmitted to up to $93 \%$ of the progeny rather than the expected $50 \%$ (the exact transmission ratio depended on the particular allele). Braden (1958) demonstrated that when mice were allowed to mate only after the female had ovulated ("late-mated" pairs) the transmission ratio of the $t$ allele dropped and in some cases approached the expected $50 \%$. The results of McGrath \& Hillman $(1980 \mathrm{a}, \mathrm{b})$ indicate that in-vitro fertilization with spermatozoa from males carrying the $t^{12}$ and $t^{6}$ alleles also results in a reduction in the transmission of these alleles, and that this lower transmission ratio does not differ significantly from that observed after late matings.

Since evidence has been presented that (in some cases at least) males heterozygous for $t$ produce equal quantities of $t$ and non- $t$ ( + or T) spermatozoa (Bryson, 1944; Yanagisawa, Pollard, Bennett, Dunn \& Boyse, 1974), much interest has been shown in the nature of the two sperm types. Spermatozoa carrying $t$ alleles have been shown to be less motile than those with the wild-type or $\mathrm{T}$ allele (Tessler, Carey \& Olds-Clarke, 1981) and with a different pattern of transport within the female (Tessler \& Olds-Clarke, 1981). Yanagisawa et al. (1974) present evidence of the greater longevity of $t$-bearing spermatozoa, and Ginsberg \& Hillman (1974) show that they have an increased rate of oxygen uptake, indicating an increased rate of metabolism in comparison with spermatozoa carrying the + or T allele. Silver \& White (1982) describe a protein coded for by a gene within the $t$-complex that is associated with the surface of the testis cell. There is also evidence that spermatozoa from $t^{\mathrm{w} 32} /+$ males penetrate eggs more rapidly in vivo (Olds-Clarke \& Becker, 1978 ) and in vitro (Olds-Clarke \& Carey, 1978) than do spermatozoa from congenic $+/+$ males.

Since the two populations of spermatozoa in our chimaeric males are derived from cells of two distinct inbred strains, differences between them may reflect gene expression during the diploid phase of spermatogenesis, and not (as in the case of the $t$ locus) the haploid phase. Burgoyne (1975) has shown that the sperm morphology characteristic of a mouse inbred strain is retained even when the spermatozoon develops in a chimaeric testis. There are a number of possible ways in which one sperm type might prove more successful than another in producing young.

First, the possible role of the female in sperm selection during transport must be considered. The uterotubal junction of the mouse appears to act as a barrier to morphologically abnormal spermatozoa (Krzanowska, 1974; de Boer, van der Hoeven \& Chardon, 1976). Although some abnormal spermatozoa can traverse the junction, the proportion of such spermatozoa is much lower in the oviduct than in the uterus (Krzanowska, 1974). In many species, mixed inseminations of females with equal numbers of spermatozoa from two males can result in a consistent 'superiority' of one male in siring offspring. Overstreet \& Adams (1971) have shown that, in the rabbit, this superiority can be correlated with more efficient sperm transport in the female tract. Cohen \& McNaughton (1974) have demonstrated that spermatozoa removed from the rabbit oviduct have a 
greater than expected chance of successfully fertilizing an egg when mixed with newly ejaculated spermatozoa and re-inseminated into the uterus of a second female, implying that oviducal spermatozoa may have been selected by the first female tract according to some criterion that allows them to succeed equally well in the second.

Some evidence does, therefore, exist that the female reproductive tract may be able selectively to restrict or enhance the transport of spermatozoa on the basis of their morphological or physiological properties. Should this selective ability be altered according to the ovulatory state of the female, a mechanism could exist to account for the shift in progeny type that occurs when mating time is changed.

Alternatively, the mechanism may involve factors intrinsic to the spermatozoon alone. A rapid capacitation time would be advantageous in the post-ovulatory matings, when the interval between coitus and fertilization is short ( $\leqslant 2 \mathrm{~h}$ : Braden \& Austin, 1954). In many animals, including sheep (Hunter, Barwise \& King, 1982), pigs (Hunter, 1981), rabbits (Turnbull, 1966), hamsters (Yanagimachi \& Chang, 1963), rats (Shalgi \& Kraicer, 1978) and guinea-pigs (Yanagimachi \& Mahi, 1976), sperm transport through the female tract is particularly rapid around the time of, and immediately after, ovulation, thus further increasing the competitive advantage of spermatozoa with a rapid capacitation time inseminated shortly after ovulation.

The data do not rule out the possibility that differential survival of embryos might account for the shift in genotype frequency in late-mated litters. Delaying mating until after ovulation results in an increased post-ovulatory age of the oocyte at the time of fertilization. Shalgi \& Kraicer (1978) observed that the interval between the time of sperm penetration and the time of first cleavage of rat eggs can be shortened by delaying mating until after ovulation. Physiological changes can thus take place in the ageing oocyte which could affect its subsequent development, and it is possible that one sperm type might be more successful than another in supporting development in these circumstances. The fact that litter size is reduced in the litters derived from daytime matings (Table 5) suggests that some eggs or embryos have not survived, and that differential death of albino embryos, rather than differential success of C57BL spermatozoa, could be responsible for the fall in the proportion of albino embryos born in these litters. However, if this were the case, one would expect to find the mean number of agouti young in litters from overnight and daytime matings to be the same, even though the proportion of agouti in the litters from daytime matings is higher. In fact (Table 5) the mean number of agouti young is signficantly higher in the daytime-mated litters of both males, indicating that differential death of albinos cannot alone account for their low frequency in these litters.

Table 5. Litter size and number of agouti progeny in litters from adlibitum, overnight and daytime matings

\begin{tabular}{clccc}
\hline Male & Mating type & $\begin{array}{c}\text { No. of } \\
\text { litters }\end{array}$ & $\begin{array}{c}\text { Mean } \\
\text { litter size }\end{array}$ & $\begin{array}{c}\text { Mean no. of } \\
\text { agouti offspring }\end{array}$ \\
\hline \multirow{2}{*}{18} & Ad-libitum & 18 & $7 \cdot 4$ & 2.5 \\
& Overnight & 8 & 6.6 & 1.5 \\
& Daytime & 9 & 6.2 & 4.9 \\
19 & Ad-libitum & 19 & $7 \cdot 2$ & 3.5 \\
& Overnight & 4 & 9.0 & 1.5 \\
& Daytime & 5 & 5.6 & 4.8 \\
\hline
\end{tabular}

The interlitter variation in genotype frequency that has previously been observed in litters sired by chimaeric males (McLaren, 1975; Gearhart \& Oster-Granite, 1981) may thus to a large degree be due to natural variations in the time of mating relative to ovulation in the female, although the nature of the mechanism by which sperm or embryo selection is accomplished remains to be elucidated. The one reported case in which no interlitter variation was seen in the progeny of 
male chimaeras (E. T. Mystkowska, personal communication to McLaren, 1975) is of interest, as in that case the two strains from which the chimaeras were derived were very closely related, and the two sperm types may not have differed sufficiently to allow a selection mechanism to operate.

Since the results from ad-libitum matings resembled those from overnight pairings in the present study, most of the ad-libitum matings probably took place, as would be expected, during the night. Litters containing predominantly albino or agouti progeny appear to be characteristic of overnight and daytime matings respectively; the fact that heterogeneity still remains in litters from overnight and daytime pairings suggests that our arbitrary division of the 24 -h period into two parts does not correspond exactly with the relevant reproductive division, and that the anomalous litters in each series have been sired in a morning or evening 'overlap' period.

Analysis of GPI from sections of seminiferous tubules from the testes of Chimaera 18 provides a more direct assay of the relative contribution of each cell type to the germ-cell population than does the analysis of breeding records. Since it did not prove possible to isolate spermatozoa from the vasa deferentia, we do not know if, in this chimaera, the production of functional spermatozoa from progenitor cells occurs at the same rate in BALB/c and C57BL cells. However, the fact that the mean relative activity of GPI-1A in both testes is $59 \%$ while the proportion of albino young from the ad-libitum matings is $66 \%$ indicates that, in this case at least, there is no great discrepancy between estimates of relative proportions of germ cell types made by the analysis of breeding records and those made by more direct biochemical means.

It is clear from these results that some care must be taken in the interpretation of breeding records of male chimaeras, especially if they are being used as an indication of the proportion of the two types of germ cells in the gonad. For instance, in the case of our chimaeras, estimates of the proportion of BALB/c germ cells could have varied from about $20 \%$ to about $80 \%$, depending on which mating protocol was being followed. The estimate from GPI analysis of testicular germ cells $(59 \%)$ diverged significantly from the daytime-mating estimate $(21 \%)$ but not from the ad-libitum $(66 \%)$ or night-mating $(77 \%)$ estimates. However, male chimaeras of other strain combinations (or indeed any mixed inseminations of different sperm types) might well prove to show different patterns of progeny variation in normal and late matings.

We thank Jack Cohen for his helpful comments, and Judy Green and Richard Gardner for the use of the Gelman scanner.

\section{References}

Bellvé, A.R., Millette, C.F., Bhaturgar, Y.M. \& O'Brien, D.A. (1977) Dissociation of the mouse testis and characterization of isolated spermatogenic cells. $J$. Histochem. Cytochem. 25, 480-494.

Bowman, P. \& McLaren, A. (1970) Viability and growth of mouse embryos after in vitro culture and fusion. $J$. Embryol. exp. Morph. 23, 693-704.

Braden, A.W.H. (1957) The relationship between the diurnal light cycle and the time of ovulation in mice. J. exp. Biol. 34, 177-188.

Braden, A.W.H. (1958) Influence of the time of mating on the segregation ratio of alleles at the $T$ locus in the house mouse. Nature, Lond. 181, 786-787.

Braden, A.W.H. \& Austin, C.R. (1954) Fertilization of the mouse egg and the effects of delayed coitus and of hot-shock treatment. Aust. J. biol. Sci. 7, 552-565.

Bryson, V. (1944) Spermatogenesis and fertility in Mus musculus as affected by factors at the T-locus. $J$. Morph. 74, 131-187.

Buehr, M. \& McLaren, A. (1981) An electrophoretically detectable modification of glucose phosphate isomer- ase in mouse spermatozoa. J. Reprod. Fert. 63, 169173.

Burgoyne, P.S. (1975) Sperm phenotype and its relationship to somatic and germ line genotype: a study using mouse aggregation chimaeras. Devl Biol. 44, 63-76.

Cohen, J. \& McNaughton, D.C. (1974) Spermatozoa: the probable selection of a small population by the genital tract of the female rabbit. J. Reprod. Fert. 39, 297-310.

de Boer, P., van der Hoeven, F.A. \& Chardon, J.A.P. (1976) The production, morphology, karyotypes and transport of spermatozoa from tertiary trisomic mice and the consequences for egg fertilization. J. Reprod. Fert. 48, 249-256.

Dunn, L.C. \& Gluecksohn-Schoenheimer, S. (1939) The inheritance of taillessness (anury) in the house mouse. II. Taillessness in a second balanced lethal line. Genetics, Princeton 24, 587-609.

Gearhart, J. \& Oster-Granite, M.L. (1981) Reproduction in a population of chimeric mice: relationship of chromsomal sex to functional germ cells and propor- 
tions of chimeric components in several tissues. Biol. Reprod. 24, 713-722.

Ginsberg, L. \& Hillman, N. (1974) Meiotic drive in $t^{\text {n- }}$ bearing mouse spermatozoa: a relationship between aerobic respiration and transmission frequency. $J$. Reprod. Fert. 38, 157-163.

Hunter, R.H.F. (1981) Sperm transport and reservoirs in the pig oviduct in relation to the time of ovulation. $J$. Reprod. Fert. 63, 109-117.

Hunter, R.H.F., Barwise, L. \& King, R. (1982) Sperm transport, storage and release in the sheep oviduct in relation to the time of ovulation. Br. vet. J. 138, 225232.

Krzanowska, H. (1974) The passage of abnormal spermatozoa through the uterotubal junction of the mouse. J. Reprod. Fert. 38, 81-90.

McGrath, J. \& Hillman, N. (1980a) The in vitro transmission frequency of the $t^{12}$ mutation in the mouse. J. Embryol. exp. Morph. 60, 141-151.

MeGrath, J. \& Hillman, N. (1980b) The in vitro transmission of the $t^{6}$ allele. Nature, Lond. 283, 479481.

McLaren, A. (1975) Sex chimaerism and germ cell distribution in a series of chimaeric mice. J. Embryol. exp. Morph. 33, 205-216.

McLaren, A. (1978) Reproduction in single-sex chimaeras. In Genetic Mosaics and Chimeras in Mammals, pp. 125-134. Ed. L. B. Russell. Plenum Press, New York.

McLaren, A. \& Buehr, M. (1981) GPI expression in female germ cells of the mouse. Genet. Res. 37, 307309.

Olds-Clarke, P. \& Becker, A. (1978) The effect of the T/t locus on sperm penetration in vivo in the house mouse. Biol. Reprod. 18, 132-140.
Olds-Clarke, P. \& Carey, J.E. (1978) Rate of egg penetration in vitro accelerated by $T / t$ locus in the mouse. J. exp. Zool. 206, 323-332.

Overstreet, J.W. \& Adams, C.E. (1971) Mechanisms of selective fertilization in the rabbit: sperm transport and viability. J. Reprod. Fert. 26, 219-231.

Shalgi, R. \& Kraicer, P.F. (1978) Timing of sperm transport, sperm penetration and cleavage in the rat. J. exp. Zool. 204, 353-360.

Silver, L.M. \& White, M. (1982) A gene product of the mouse t-complex with chemical properties of a cell surface-associated component of the extracellular matrix. Devl Biol. 91, 423-430.

Tessler, S. \& Olds-Clarke, P. (1981) Male genotype influences sperm transport in female mice. Biol. Reprod. 24, 806-813.

Tessler, S., Carey, J.E. \& Olds-Clarke, P. (1981) Mouse sperm motility affected by factors in the $\mathrm{T} / \mathrm{t}$ complex. J. exp. Zool. 217, 277-285.

Turnbull, K.E. (1966) The transport of spermatozoa in the rabbit doe before and after ovulation. Aust. $J$. biol. Sci. 19, 1095-1099.

Yanagimachi, R. \& Chang, M.C. (1963) Sperm ascent through the oviduct of the hamster and rabbit in relation to the time of ovulation. J. Reprod. Fert. 6, 413-420.

Yanagimachi, R. \& Mahi, C.A. (1976) The sperm acrosome reaction and fertilization in the guinea pig: a study in vivo. J. Reprod. Fert. 46, 49-54.

Yanagisawa, K., Pollard, D.R., Bennett, D., Dunn, L.C. \& Boyse, E.A. (1974) Transmission ratio distortion at the t-locus: serological identification of two sperm populations in t-heterozygotes. Immunogenetics 1, 9196.

Received 9 February 1984 